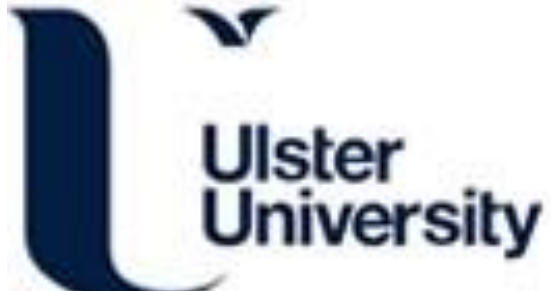

\section{Link Characteristics for an Off-Body UWB Transmitter in a Hospital Environment}

Catherwood, P., \& Scanlon, W. (2009). Link Characteristics for an Off-Body UWB Transmitter in a Hospital Environment. In Unknown Host Publication (pp. 569-572). IEEE Xplore.

https://doi.org/10.1109/LAPC.2009.5352391

Link to publication record in Ulster University Research Portal

\section{Published in:}

Unknown Host Publication

Publication Status:

Published (in print/issue): 01/01/2009

DOI:

10.1109/LAPC.2009.5352391

\section{Document Version}

Author Accepted version

\section{General rights}

Copyright for the publications made accessible via Ulster University's Research Portal is retained by the author(s) and / or other copyright owners and it is a condition of accessing these publications that users recognise and abide by the legal requirements associated with these rights.

\section{Take down policy}

The Research Portal is Ulster University's institutional repository that provides access to Ulster's research outputs. Every effort has been made to ensure that content in the Research Portal does not infringe any person's rights, or applicable UK laws. If you discover content in the Research Portal that you believe breaches copyright or violates any law, please contact pure-support@ulster.ac.uk. 


\title{
Link Characteristics for an Off-Body UWB Transmitter in a Hospital Environment
}

\author{
Philip A. Catherwood, William G. Scanlon \\ Institute of Electronics, Communications \& Information Technology (ECIT), \\ Queen's University of Belfast, Belfast, BT3 9DT, UK \\ philip.catherwoodenrc.ac.uk \\ w. scanlon@qub.ac.uk
}

\begin{abstract}
This paper presents both stationary and mobile signal strength measurements for a wearable UWB radio channel in a hospital environment. The measurements were made using RFover-fibre technology to eliminate unwanted electromagnetic effects associated with the use of co-axial cables. The results show that received signal strength values depended on whether transmit and receive antennas are in relative line of sight or non line of sight conditions. For mobile tests, both line of sight and non line of sight conditions tended to have lognormally distributed fading with the latter having significantly lower mean signal strength. For stationary conditions, signal strength was also dependant on user mode, with the difference between standing and sitting in the same location being up to $5.3 \mathrm{~dB}$.
\end{abstract}

\section{INTRODUCTION}

It is envisaged that reliable high speed mobile wireless data access will become a routine feature of modern health care [1]. In patient monitoring, sensors are placed on the body and connected via cables to various electronic devices that process and display the data, including vital signs such as respiration rate, oxygen saturation and electrocardiogram. On occasion these cables between patient and machine can complicate treatment and also make it difficult to transport patients without an interruption in monitoring [2]. Introducing wireless monitoring addresses these issues and allows an increase in mobility and patient comfort [1].

The transmission of data from the wireless sensor nodes to the hospital network is a key topic that has attracted much recent interest [3], [4]. It is clear from this recent research work that various wireless data transmission technologies can be used, including Wi-Fi, Bluetooth, UWB, Zigbee, etc, with many commercial devices opting for Bluetooth [5]. However, for areas less than $15 \mathrm{~m}$ UWB offers very low power, cost, complexity and very high data rates [6]. In medical applications UWB would be suitable for transmitting sizable volumes of streamed patient data within indoor hospital environments as it is less affected by multipath propagation than other competing technologies. It is thus suitable for a busy ward environment with furniture and pedestrians blocking the line of sight (LOS) path between transmitter (TX) and receiver (RX) [7]. It is also hospital safe since the low level of emissions [8] will not impinge on other wireless systems.

Currently only a few studies have addressed the topic of UWB radio links in hospitals [9] and some have also considered wearable terminals [10], [11]. However, to date, no study has been reported on stationary and mobile path loss for an on-body UWB wireless link within hospital environments. Hence, the purpose of this paper is to report off-body UWB radio channel results for a hospital ward environment. Section II describes the measurements system utilised, the environment and the test procedure. Section III reports on the experimental results, Section IV highlights conclusions.

\section{MeAsurement System, ENVIRONMENT AND Procedure}

\section{A. Measurement System}

The wearable transmitter (Fig. 1) consisted of a single UWB antenna (Fractus UM-FR05-S1-P-0-107) connected to a battery powered UWB PulsON ${ }^{1}$ source using $1550 \mathrm{~nm}$ RFover-fibre components. The source was FCC compliant with a centre frequency of $4.7 \mathrm{GHz}$, a bandwidth of $3.2 \mathrm{GHz}$ and a launch power of $-12 \mathrm{dBm}$. The RF-over-fibre system used had a gain of $0-\mathrm{dB}$ and it eliminated the electromagnetic coupling effects associated with RF cables. The transmitted signals were received by a PulsON UWB receiver system using a vertically polarized PulsON UWB antenna.

(a)

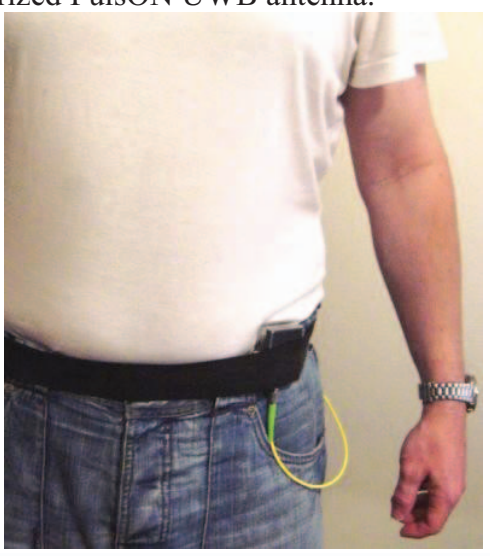

(b)

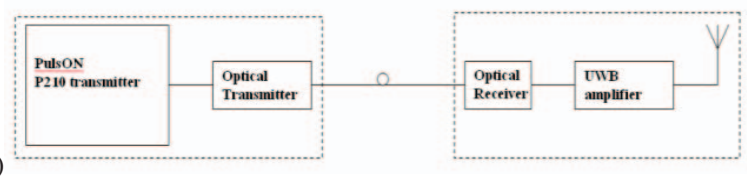

Fig. 1 Wearable UWB transmitter a) antenna and amplifier unit on user's waist showing optical feed, b) block diagram.

\footnotetext{
${ }^{1}$ http://www.timedomain.com/pulson.php
} 
A laptop running PulsON software recorded received data at a rate of 100 samples per second which is sufficient for a $6 \mathrm{GHz}$ node moving at $0.5 \mathrm{~ms}^{-1}$ (the Doppler frequency for such a mobile transmitter is $10 \mathrm{~Hz}$ ).

\section{B. Environment}

The measurement campaign was undertaken in a specialist nurse training room in the University of Ulster at Coleraine in Northern Ireland (Fig. 2). This $49 \mathrm{~m}^{2}$ training room faithfully recreates a real hospital ward and is fitted with UK National Health Service specification beds, rails, bedside cabinets, etc. The building was of 1960's construction, consisting mainly of double concrete-block cavity external walls, single brick internal walls and concrete floor. A suspended ceiling supports luminaries at $2.8 \mathrm{~m}$ above floor level. This would be in keeping with many established hospitals in the UK.

\section{Procedure}

The receiver was placed between beds \#2 and \#3 at a height of $2.2 \mathrm{~m}$ to represent a base-station access point. The wearable transmitter was positioned at the user's waist $(1.05 \mathrm{~m}$ above floor level) with the antenna held against the body using an adjustable cloth elastic band to minimise body-antenna separation during testing. The test user was an adult male of mass $82 \mathrm{~kg}$, height $1.78 \mathrm{~m}$. The measurement system periodically records the channel impulse response (CIR) of the transmitted UWB signal. A reference signal strength measurement was recorded for a direct LOS for a TX-RX separation of $3.2 \mathrm{~m}$, as required by the PulsON system to establish an accurate datum. This reference value is considered as an ideal link scenario to which all others can be compared. The tests were split into 2 categories; stationary and mobile measurements. The mobile tests were either LOS or non-LOS (NLOS), depending on the orientation of the user.

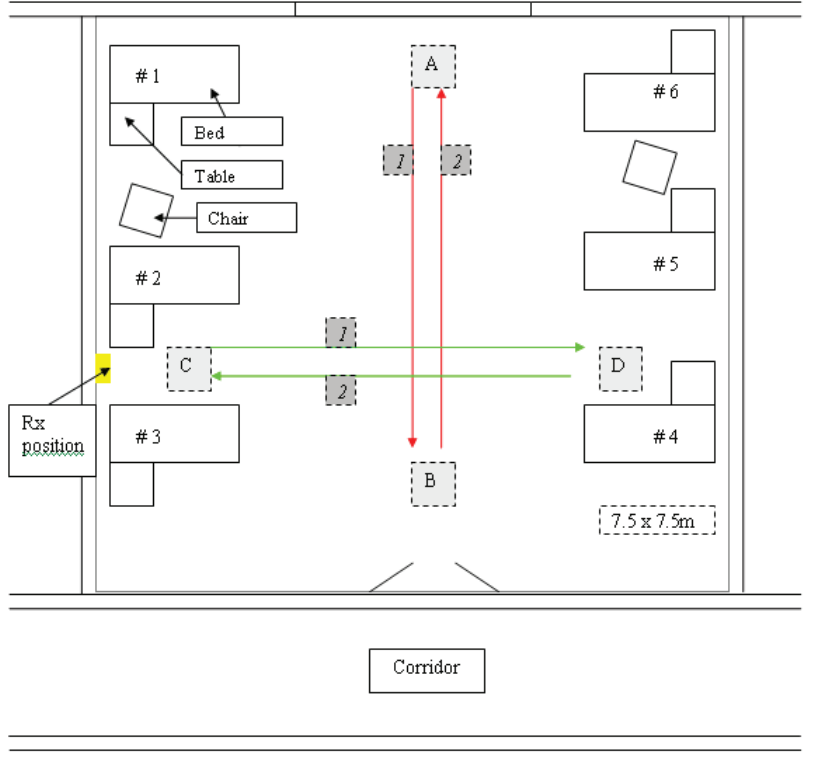

Fig. 2 Plan view of environment.
1) Stationary tests - TX on waist at position \#2 and \#6.

- User standing beside bed

- User sitting in chair

- User sitting in bed

- User lying (face-up) in bed

2) Mobile tests $-T X$ on waist; speed $=0.5 \mathrm{~m} / \mathrm{s}$.

- User mobile A to B (LOS - red path 1)

- User mobile B to A (NLOS - red path 2)

- User mobile C to D (LOS - green path 1)

- User mobile D to C (NLOS - green path 2)

- User moves without restriction (random walk)

All tests, except for those for the user in a bed, are applicable for either a patient or a clinician wearing a UWB data terminal. The received power profiles were calculated from the recorded CIR samples using Matlab. The study of received power is of interest as it gives an understanding of typical path loss characteristics for off-body links in the ward environment, taking into account all relevant factors including body-interaction effects and shadowing caused by furniture and fittings.

\section{RESULTS}

\section{A. Stationary Tests}

The stationary results in Table 1 show that a standing position ensured the highest signal strengths, with the worst case being a seated position. This is unsurprising as the seated position suffered from increased body-shadowing effect, increased TX/RX height differential and also signal blocking due to the metal beds between the seat and the receiver. It was also observed that sitting upon the bed had a marginal effect on relative path loss, whereas lying on the bed caused much higher reductions in received power. This is most likely to have been caused by the change in polarization and orientation of the transmitter antenna with respect to that of the receive antenna. It was also noted that the mean signal strength at position \#6 was higher than at \#2, despite the latter being much closer to the receiver (\#6 was $7.3 \mathrm{~m}$ from the RX, while \#2 was only $1.9 \mathrm{~m}$ away). This is directly related to position \#2 being NLOS (patient facing away from the receiver thus blocking the signal path), whereas position \#6 was direct LOS.

TABLE I

SIGNAL STRENGTH RESULTS FOR EXPERIMENTAL TESTS

\begin{tabular}{|c|c|c|}
\hline $\begin{array}{c}\text { Ward } \\
\text { location }\end{array}$ & $\begin{array}{c}\text { Patient } \\
\text { position }\end{array}$ & $\begin{array}{c}\text { Signal strength w.r.t. } \\
\text { reference (dB) }\end{array}$ \\
\hline \multirow{4}{*}{$\# \mathbf{2}$} & Standing & -2.4 \\
\cline { 2 - 3 } & Sitting (chair) & -7.7 \\
\cline { 2 - 3 } & Sitting (bed) & -2.7 \\
\cline { 2 - 3 } & Lying (bed) & -6.7 \\
\hline \multirow{4}{*}{$\# \mathbf{6}$} & Standing & -1.1 \\
\cline { 2 - 3 } & Sitting (chair) & -5.8 \\
\cline { 2 - 3 } & Sitting (bed) & -1.4 \\
\cline { 2 - 3 } & Lying (bed) & -4.8 \\
\hline
\end{tabular}




\section{B. Mobile Tests}

The received power data for each of the 5 mobile tests was organised into bins according to the Freedman-Diaconis rule. Fig. 3 shows an example received power time series for the user walking from $\mathrm{C}$ to $\mathrm{D}$ (LOS). Note the dynamic range of almost $25 \mathrm{~dB}$ and the relatively deep 'fades' in path loss. Each time series was transformed into a cumulative density function (CDF) that was compared to theoretical statistical distributions (Rician, lognormal, Rayleigh, Nakagami, Gamma, etc.) as a basis for modelling of the radio channel.

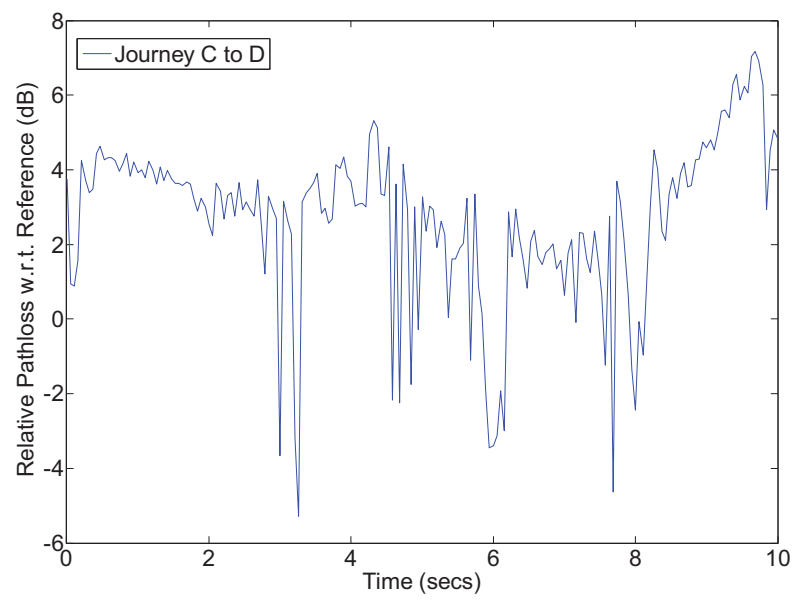

Fig. 3 Time series for user moving for C to D (LOS).

The CDF for the LOS journeys for paths A-B (LOS), B-A (NLOS), C-D (LOS) and D-C (NLOS) are shown in Figs. 47 , respectively. The CDF for the random walk is shown in Fig. 8. Overall, it was found that the lognormal distribution was the best fit in each case, regardless of type of link (LOS or NLOS) and path chosen.

Nonetheless, there are differences in the details for each path, as shown in Table II. The highest mean power was recorded for journey $\mathrm{C}-\mathrm{D}$ and the lowest mean power for journey B-A. However, the dominant factor in the tests was whether the antennas were in LOS, with an average of $6.6 \mathrm{~dB}$ difference between NLOS and LOS for the linear paths. Dynamic range was found to be determined by the path followed rather than LOS conditions, with almost $12.4 \mathrm{~dB}$ for the linear path A to B compared to $8.5 \mathrm{~dB}$ for $\mathrm{C}$ to $\mathrm{D}$. The unconstrained movement test (random walk) saw the largest dynamic range of $19.2 \mathrm{~dB}$. This reflects the wide range of differing scenarios the system was placed under during the test, such as LOS, NLOS, shadowing, reflections, etc. This resulted in both the highest received power values and the deepest fades. This test perhaps best reflects real-life usage of an UWB system in a dynamic hospital environment.

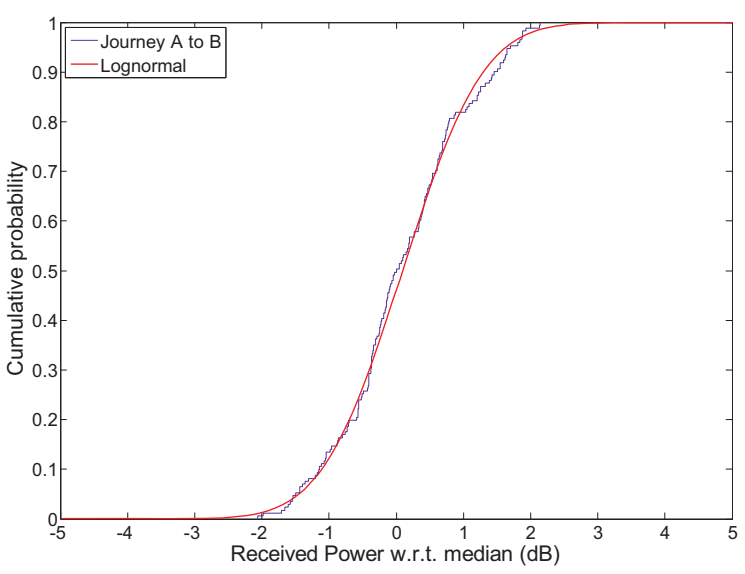

Fig. 4 CDF for LOS journey from A to B.

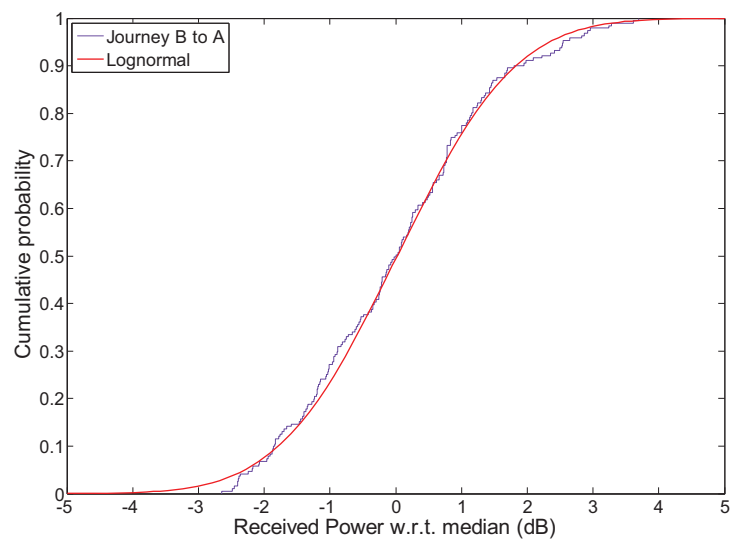

Fig. 5 CDF for NLOS journey from B to A.

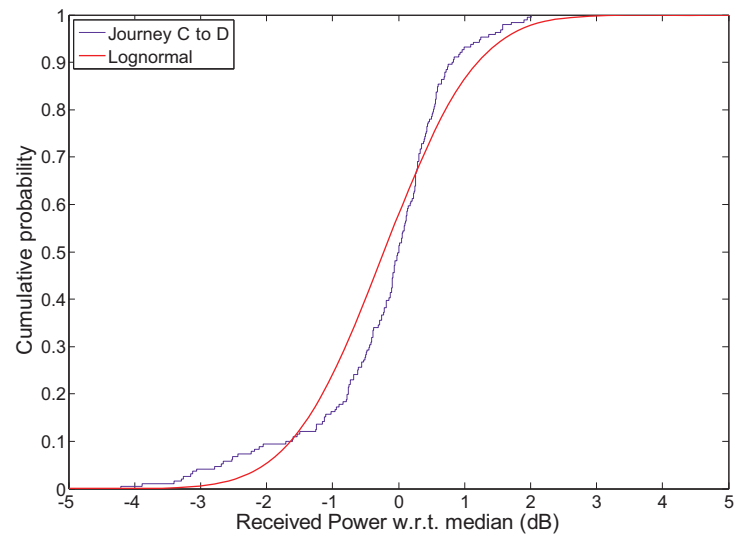

Fig. $6 \mathrm{CDF}$ for LOS journey from $\mathrm{C}$ to $\mathrm{D}$. 


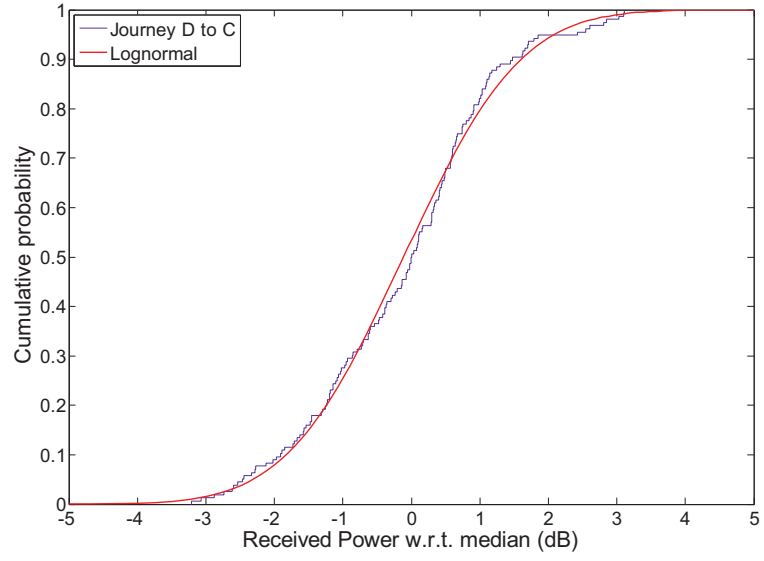

Fig. 7 CDF for NLOS journey from D to C.

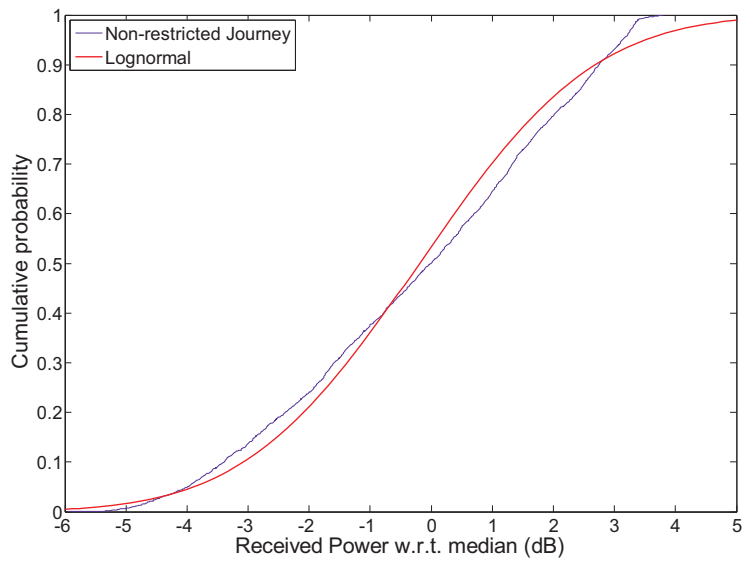

Fig. $8 \mathrm{CDF}$ for random walk.

TABLE II

LINK CHARACTERISTICS FOR MOBILE TESTS (MEAN RELATIVE TO REFERENCE)

\begin{tabular}{|l|c|c|c|c|c|}
\hline Journey & $\begin{array}{c}\text { A-B } \\
\text { LOS }\end{array}$ & $\begin{array}{c}\text { B-A } \\
\text { NLOS }\end{array}$ & $\begin{array}{c}\text { C-D } \\
\text { LOS }\end{array}$ & $\begin{array}{c}\text { D-C } \\
\text { NLOS }\end{array}$ & $\begin{array}{c}\text { Random } \\
\text { walk }\end{array}$ \\
\hline Mean & 2.3 & -3.3 & 2.8 & -4.7 & -0.41 \\
\hline Std dev & 1.8 & 2.8 & 2.2 & 2.6 & 4.5 \\
\hline Max & 6.4 & 4.0 & 7.2 & 1.8 & 6.9 \\
\hline Min & -2.1 & -8.7 & -5.2 & -10.9 & -12.3 \\
\hline Range & 8.5 & 12.7 & 12.4 & 12.7 & 19.2 \\
\hline $\begin{array}{l}\text { LOS v's } \\
\text { NLOS }\end{array}$ & & 5.6 & & 7.5 & \\
\hline
\end{tabular}

\section{CONCLUSIONS}

Relative path loss results for both the stationary and mobile off-body UWB radio channel have been presented. The measurements were made in a realistic hospital ward environment using RF-over-fibre technology. The mobile results show that the variation in total received power for a waist worn transmitter are well described by a lognormal distribution, but that the mean levels and dynamic range were dependent on the nature of the path and line of sight conditions. Stationary experiments highlighted that received power was dependent on user orientation as well as the multipath hospital environment. Future work will investigate the effect of the position of the UWB antenna on the body and, after characterising the wideband channel parameters recorded for these experiments, will lead to a full off-body UWB channel model for the hospital environment.

\section{ACKNOWLEDGMENT}

The authors wish to acknowledge the kind support of the School of Nursing at the University of Ulster for access and use of the training room facilities.

\section{REFERENCES}

[1] A. Taparugssanagorn et al, "UWB channel modeling for wireless body area networks in medical applications," $3^{\text {rd }}$ Intl. Symp. on Medical Info. \& Comm. Tech., Montreal, Canada. 5 p., 2009.

[2] M. Paksuniemi et al, "Wireless sensor and data transmission needs and technologies for patient monitoring in the operating room and intensive care unit," Proc. $27^{\text {th }}$ Annual IEEE Eng. in Medicine and Biology Conf., Shanghai, China, pp. 5181-5185, 2005.

[3] D. I Shin, S. J. Huh, and P. J. Pak, "Patient monitoring system using sensor network based on the ZigBee radio," $6^{\text {th }}$ Intl. Conf. Information Technology Applications in Biomedicine, Tokyo, pp. 313- 15, 2007.

[4] M. Karlsson et al, "Wireless system for real-time recording of heart rate variability for home nursing," Proc. 27 th Annual IEEE Eng. in Medicine and Biology Conf., Shanghai, China, pp. 3717-3719, 2005.

[5] ST\&D - http://www.std-ltd.com/devices-overview.htm.

[6] IEEE.802.15.3A (TG3a) standard [Online]. Available: www.ieee802.org/15/pub/TG3a.html

[7] I. Oppermann (Ed.), UWB theory and application. Wiley, UK, 2004.

[8] Code of Federal Regulations (CFR), Title 47-Telecomms, Chapter I, Part 15-Radio Frequency devices. Sect. 15.517 "Technical requirements for indoor UWB systems", pg 846-847, 10/104.

[9] L. Hentila et al, "Measurement and modelling of an UWB channel at hospital," IEEE Intl. Conf. Ultra-Wideband, 2005.

[10] K. Takizawa et al, "Channel models for wireless body area networks," Proc. $30^{\text {th }}$ Annual IEEE Eng. in Medicine and Biology Conf., pp. 15491552,2008

[11] A. Sani et al, "Time domain characterisation of ultra wideband wearable antennas and radio propagation for body-centric wireless networks in healthcare applications," $5^{\text {th }}$ Intl. Workshop Wearable \& Implantable Body Sensor Networks (BSN 2008), Hong Kong, 2008. 